Reviews

\title{
The Process of Business/Environmental Collaborations: Partnering for Sustainability, by Alissa J. Stern with Tim Hicks. Westport, CT: Quorum Books, (2000), 204 pp.
}

\section{Reviewed by Jill M. Purdy, School of Business Administration, University of Washington- Tacoma.}

The Process of Business/Environmental Collaborations accomplishes the purposes outlined by its authors: to help business and environmental leaders decide whether to collaborate and how to collaborate. Collaboration's goal is simple: to create partnerships between organizations and environmental groups who have traditionally been adversaries. The notion of collaboration has been written about extensively, but many of books on the subject are now more than a decade old [1]. This book successfully builds upon these earlier works to provide a comprehensive guide that is aimed at the people who may engage in collaboration. In writing for an audience of business people and environmentalists, the authors offer practical information and relevant examples that illuminate when and how collaboration might be done. Overall, the book is well written, clear and readable, although printing errors provide numerous distractions from the book's content (one 25-page section contains five typographical errors). Some confusion is created by the haphazard insertion of case examples throughout the text, but the practical advice that can be gleaned from the book make it worthwhile reading.

Although most of the book focuses on how to engage in collaboration, the book is more than a how-to guide. A drawback to many process guides is that the authors assume that one can and should engage in the process described in the book. This is of particular concern in the field of collaboration where most of the books about mediation, ãwin-winä negotiating, and other forms of collaboration assume without comment that collaboration is better than the alternatives. In contrast, Stern and Hicks do not paint collaboration as a panacea for business / environmental disputes. They encourage deliberation about whether to collaborate and they provide tools to assist the reader in making an informed decision. Chapter Two provides a very useful framework to help organizations determine whether or not to participate in collaboration based on their organization's values, the costs, the demands of the process, and the possible outcomes. The book presents an even-handed look at collaboration's costs and problems as well as its benefits and opportunities.

The collaborative process serves as the organizing scheme for Chapters Three through Nine, which comprise the bulk of the book's 204 pages. In these chapters, the authors provide advice on five major tasks of collaborating: gaining internal support, convening the parties, developing ground rules and strategy, negotiating agreements, and documenting and monitoring. The authors' experience with collaboration is evident in the thorough discussion of each task. Real world issues that might cause a first-time collaborator concern are addressed matter-of-factly. For example, a section on confidentiality acknowledges that environmental organizations may be reluctant to agree to confidentiality because they value public scrutiny, while businesses may be reluctant to share information regardless of confidentiality agreements. Rather than suggesting simple solutions to complex concerns such as these, the book makes readers aware of the issues and encourages them to devise solutions appropriate for their situations.

Following their discussion of the collaboration process, Stern and Hicks provide practical advice for when and how to involve outside parties such as the government, the media, and the public. In addition, they describe how mediators, technical experts, and trainers can aid the collaboration process and suggest criteria for selecting them. Given that no universal standards exist for private mediators, advice on how to locate a qualified mediator would have been a welcome addition to this book. Chapter Twelve considers both philosophical and practical questions of how to evaluate progress in collaboration. The authors encourage readers to think about what success means and consider both outcomes and processes in evaluating whether a collaboration has been successful. The chapter goes on to discuss evaluation procedures in some depth, addressing who should conduct the evaluation, who should participate in the evaluation, and when to conduct evaluation. This authors make a convincing argument that evaluation is crucial to fostering learning for all parties involved in collaboration. Useful back matter rounds out the book, with a glossary, a bibliography and an appendix listing recent environmental collaborations.

The book's strength is its practical narrative that walks the reader through the collaboration process step by step. Regrettably, the flow of this narrative is interrupted, sometimes jarringly, by five case studies that aim to provide richer examples of collaboration. The content of the case studies is interesting and relevant, but their placement in the text serves to confuse more than to illuminate. Cases appear at the ends of Chapters Two, Four, Six, Seven and Ten, but the content of a case isn't always easily matched to the chapter in which it appears. The cases would seem to be nothing more than storytelling if not for the points at the end of each case that summarize 
Reviews

the lessons to be learned from it.

A further problem with the case studies is that in the earlier parts of the book, the authors frequently refer to the cases the reader has not yet read. In an apparent attempt to solve this problem, short synopses of all five cases are provided at the end of Chapter One, although no explanation is offered as to why these synopses appear in the text at this point. The synopses aid the reader in recognizing case references, but they don't provide sufficient detail to truly understand the examples presented. For example, one synopsis fails to mention the name of a key party to the collaboration. Without an adequate understanding of the cases, readers are left to page through the book for more information if they wish to understand an example used in the narrative. One might be well advised to read all five detailed case studies prior to reading the book in its entirety.

A final concern with the way that case studies are presented in the book is the order in which they appear. The first case presented, a description of the Rainforest Action Network's efforts to influence the forest practices of Mitsubishi Corporation, had the positive outcomes of ending a boycott and sponsoring research on improving sustainability. However, it also had the consequence of damaging relations between two U.S. subsidiaries of Mitsubishi and their parent company. Furthermore, the Rainforest Action Network failed to achieve its goal of changing Mitsubishi's forest practices. This mixed outcome collaboration is followed by a case involving Scott Paper Company in which collaboration efforts failed outright. Although these cases are important to presenting a complete picture of collaboration outcomes, one must read nearly one hundred pages before encountering an example of a collaboration success. The business person or environmentalist who picks up the book to explore the possibility of collaboration may be unduly discouraged by the first two examples offered.

Although environmental collaborations have existed for a quarter-century, relatively little has been written about them in the past ten years and few texts address private-sector environmental collaboration. The Process of Business/Environmental Collaborations responds to the field's need for an updated text that may serve both academics and practitioners. Its focus on private-sector collaboration creates a useful new source of information and examples. For those who wish to travel the path of collaboration, The Process of Business/Environmental Collaborations provides a concise, yet comprehensive guide that may enable new partnerships between business and environmentalists.

FOOTNOTE:

[1] Classic books in the area of environmental collaboration include Environmental Dispute Resolution by Lawrence Bacow and Michael Wheeler (New York: Plenum Press, 1984), Resolving Environmental Disputes: A Decade of Experience by Gail Bingham (Washington, D.C.: The Conservation Foundation, 1986) and Collaborating: Finding Common Ground for Multiparty Problems by Barbara Gray (San Francisco: Jossey-Bass, 1989).

\section{Connection on the Ice, by Patti H. Clayton. Philadelphia: Temple University Press (1998), xxiv, 303 pp.}

\section{Reviewed by Holmes Rolston III, Department of Philosophy, Colorado State University.}

Clayton uses the rescue in October 1988 of two whales at Barrow, Alaska, "one of the most remarkable animal rescues in history," as a window into the human relation to nature, our "connection" as she puts it, as "a microcosm of the human-environment interaction" [pp. xviii-xix]. She sets her window against a generally modern worldview in which, she thinks, humans have too much "detached" themselves from nature.

Clayton enjoys a story-telling environmental ethics. Her ethics is one that is lived--a pragmatic one (to use a word now much in vogue); but she steadily pursues what theory can justify the actions practiced in the story she recounts. The whale rescue was a quite public event, involving governments, even U.S./Soviet cooperation, and worldwide media coverage for three weeks. It caught up hundreds of individuals in the rescue effort and millions with a concern for animals. There is ample "connection" here between ethics and policy.

Clayton explores various ways of making sense of the whale rescue, as this might fit into a larger framework making sense of humans on the planet. She worries about "the possibility and the difficulty of building a more generalized concern from such localized concern" [p. 145]. The two schools of thought ("conceptual lenses") that 